\section{Concomitant suppression of three target genes can explain the impact of a microRNA on metastasis}

\author{
Scott Valastyan, ${ }^{1,2}$ Nathan Benaich, ${ }^{1,3}$ \\ Amelia Chang, ${ }^{1,2}$ Ferenc Reinhardt, ${ }^{1}$ \\ and Robert A. Weinberg ${ }^{1,2,4,5}$
}

\begin{abstract}
${ }^{1}$ Whitehead Institute for Biomedical Research, Cambridge, Massachusetts 02142, USA; ${ }^{2}$ Department of Biology, Massachusetts Institute of Technology, Cambridge, Massachusetts 02139, USA; ${ }^{3}$ Department of Biology, Williams College, Williamstown, Massachusetts 01267, USA; ${ }^{4}$ Massachusetts Institute of Technology Ludwig Center for Molecular Oncology, Cambridge, Massachusetts 02139, USA
\end{abstract}

It remains unclear whether a microRNA (miRNA) affects a given phenotype via concomitant down-regulation of its entire repertoire of targets or instead by suppression of only a modest subset of effectors. We demonstrate that inhibition of breast cancer metastasis by miR-31-a miRNA predicted to modulate $>\mathbf{2 0 0}$ mRNAs-can be entirely explained by miR-31's pleiotropic regulation of three targets. Thus, concurrent re-expression of integrin$\alpha 5$, radixin, and $\mathrm{RhoA}$ abrogates miR-31-imposed metastasis suppression. These effectors influence di steps of the metastatic process. Our findings ho e in plications concerning the importance of pleir to $\mathrm{v}$, or the biological actions of miRNAs and pro te ma hanistic insights into metastasis.

Supplemental material is available at http / www.gene lev.org. Received June 15, 2009; revised version ao ced September $24,2009$.

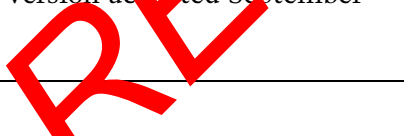

MicroRNAs (miRNAs) are an en lutionarily conserved family of regulatory RNAs that inhibit their mRNA targets post-transcriptionally, leading to modulation of diverse biological processes, including the development and progression of cancer (Ambros 2004; Bartel 2009; Ventura and Jacks 2009). An individual miRNA is capable of regulating dozens of distinct mRNAs (Baek et al. 2008; Selbach et al. 2008), and it is thought that pleiotropic suppression of multiple downstream effectors may underlie the phenotypic changes observed upon perturbing the levels of certain miRNAs (Rodriguez et al. 2007; Thai et al. 2007; van Rooij et al. 2007; Zhao et al. 2007; Johnnidis et al. 2008; Ventura et al. 2008). It remains unclear, however, whether these consequences depend on simultaneous deregulation of the entire repertoire of

[Keywords: MicroRNA; metastasis; miR-31; breast cancer; colonization; pleiotropy]

${ }^{5}$ Corresponding author.

E-MAIL weinberg@wi.mit.edu; FAX (617) 258-5213.

Article published online ahead of print. Article and publication date are online at http://www.genesdev.org/cgi/doi/10.1101/gad.1832709. targets of a given miRNA or instead on the altered activity of only a small subset of effectors.

Metastases, which are responsible for $90 \%$ of human cancer deaths, arise via a complex series of events, collectively termed the invasion-metastasis cascade (Fidler 2003; Gupta and Massagué 2006). In order to metastasize, cells in a primary tumor must become motile, degrade surrounding extracellular matrix (local invasion), intravasate into the vasculature, retain viability during transit through the circulation, extravasate into the parenchyma of a distant tissue, survive in this foreign microenvironment to form micrometastases, and, finally, thrive in their new milieu and establish macroscopic secondary tumors (colonization) (Fidler 2003). Colonization is the rate-limiting step of the invasion-metastasis cascade, yet the molecular underpinnings of this process are poorly understood (and and and 2006).

We determined ree ntly th t expression of the miRNA miR-31 was both ec sary a d sufficient to inhibit the metastasis of h man b ast cancer xenografts, and that miR-31 levels corr ated nversely with metastatic relapse in bre st d (nom patients (Valastyan et al. 2009). We attri ed th e Aects to miR-31's ability to pleiotropicany s ppres a cohort of prometastatic targets; hoy r, we did not identify a minimal set of downst eam effectors whose concomitant re-expression is su ficient o fully override miR-31's influences on metastas For this reason, we sought to determine whether the impact of miR-31 on metastasis could be explained by ability to pleiotropically modulate a defined subset of its $>200$ predicted targets.

\section{Results and Discussion}

We demonstrated previously that miR-31 regulates six mRNAs that encode proteins with roles in cell motility and tumor progression: frizzled 3 (Fzd3), integrin- $\alpha 5$ (ITGA5), matrix metallopeptidase 16 (MMP16), myosin phosphatase-Rho-interacting protein (M-RIP), radixin (RDX), and RhoA (Valastyan et al. 2009). To begin to address whether miR-31-imposed inhibition of one or more of these effectors might be responsible for mediating miR-31's anti-metastatic influences, we stably suppressed these six mRNAs individually in otherwise metastatic MDA-MB-231 human breast cancer cells ("231 cells") using shRNAs. 231 cells are largely devoid of endogenous miR-31 and robustly express these six effectors; moreover, ectopic miR-31 impairs metastasis by these cells (Valastyan et al. 2009).

For each gene, we derived multiple cell lines that stably expressed a distinct shRNA targeting unique sequences in the encoded mRNA in order to minimize confounding influences from shRNA off-target effects (Supplemental Figs. 1A, 2A). At least one shRNA against each of the six effectors reduced its target's level by a factor comparable with that elicited by miR-31 expression (Valastyan et al. 2009). This allowed us to reasonably approximate the consequences of miR-31's actions on each individual downstream effector.

These shRNA-expressing 231 cells were subjected to in vitro assays that model traits important for metastasis. We observed that individual suppression of ITGA5, RDX, or RhoA reduced invasion, motility, and resistance to 
anoikis-mediated cell death in vitro; in contrast, the Fzd3, MMP16, or M-RIP shRNAs failed to substantially affect these behaviors (Supplemental Figs. 1B-D, 2B-D). For shRNAs that conferred measurable responses, the magnitude of these responses was directly correlated with the extent of knockdown achieved, suggesting that these effects arose as a specific consequence of reduced levels of the targeted protein. Inhibition of Fzd3, ITGA5, MMP16, M-RIP, RDX, or RhoA failed to affect in vitro proliferation (Supplemental Figs. 1E, 2E). Also, the responses evoked by the ITGA5, RDX, and RhoA shRNAs could not be ascribed to saturation of the miRNA biogenesis machinery, as mature levels of eight control miRNAs were unaffected in these cells (Supplemental Fig. 3).

We determined whether suppression of these six mRNAs altered metastatic capacity in vivo by intravenously injecting the shRNA-expressing 231 cells into mice. One month later, cells bearing shRNAs targeting ITGA5, RDX, or RhoA had generated $80 \%, 85 \%$, and $55 \%$ fewer lung metastases than controls, respectively; however, down-regulation of Fzd3, MMP16, or M-RIP did not affect the number of metastases spawned (Supplemental Fig. 4). Thus, inhibition of ITGA5, RDX, or RhoA-but not Fzd3, MMP16, or M-RIP-affects in vitro surrogates of metastatic capacity as well as in vivo metastasis.

To extend these analyses, we stably re-expressed miRNA-insensitive versions of the mRNAs encoding Fzd3, ITGA5, MMP16, M-RIP, RDX, or RhoA individually in 231 cells that already expressed either miR-31 or control vector (Supplemental Fig. 5A). This allowed $u$ to gauge the ability of each of these effectors-when te expressed-to reverse miR-31's impact on in viys met tasis. When introduced into the venous cir alat on mice, miR-31-expressing cells formed $85 \%$ few lun metastases than controls 1 mo post-in ctio 1 Suppemental Fig. 5B), consistent with o prior findings (Valastyan et al. 2009). Individual re-expre ion on TGA5, RDX, or RhoA restored the numb, of lung etastases in miR-31-expressing cells to 55\% $50 \%$ and $65 \%$ of control levels, respectively; in contrast, $\nabla$, MMP16, or M-RIP failed to increase lesion $\mathrm{n} . \mathrm{m}$. $\mathrm{r}$ upp cmental Fig. 5B). Overexpression of ITGA , RD $\mathbf{L}$, or $\mathrm{NOA}$ did not further enhance metastasis in c colls (Supplemental Fig. 5B), suggesting that s. naling from these pathways was already saturated in 231 ells, as has been established previously for RhoA-controlled networks (Pillé et al. 2005). Together, these findings implied that, although miR-31 is capable of suppressing numerous mRNA species, its ability to regulate only a subset of these effectors appears to be crucial for its capacity to impair metastasis.

In support of this notion, when stably re-expressed in 231 cells, Fzd3, MMP16, or M-RIP failed to reverse miR31-imposed attenuation of invasion, motility, and anoikis resistance in vitro (Supplemental Fig. 6); in contrast, our prior work revealed that restored levels of ITGA5, RDX, or RhoA rescued, at least partially, miR-31-evoked defects in these phenotypes (Valastyan et al. 2009). Based on these in vitro and in vivo re-expression data, as well as the above-described in vitro and in vivo loss-of-function findings, we focused our subsequent analyses on the ability of inhibition of ITGA5, RDX, and RhoA to account for miR-31's anti-metastatic activities.

To this end, we investigated the consequences of suppressing ITGA5, RDX, or RhoA individually in an orthotopic injection assay. Accordingly, we implanted
231 cells expressing shRNAs targeting either ITGA5, RDX, or RhoA into the mammary fat pads of mice. Suppression of ITGA5 or RhoA did not affect primary tumor growth; conversely, inhibition of RDX reduced the size of resulting mammary tumors (Fig. 1A). After normalizing for differences in primary tumor growth, cells expressing shRNAs against ITGA5, RDX, or RhoA formed $85 \%, 70 \%$, and $50 \%$ fewer lung metastases than controls $2.5 \mathrm{mo}$ after injection, respectively (Fig. 1B). Thus, inhibition of ITGA5, RDX, or RhoA each impedes metastasis; however, this assay did not reveal the particular step(s) of the invasion-metastasis cascade that were impaired due to suppression of ITGA5, RDX, or RhoA.

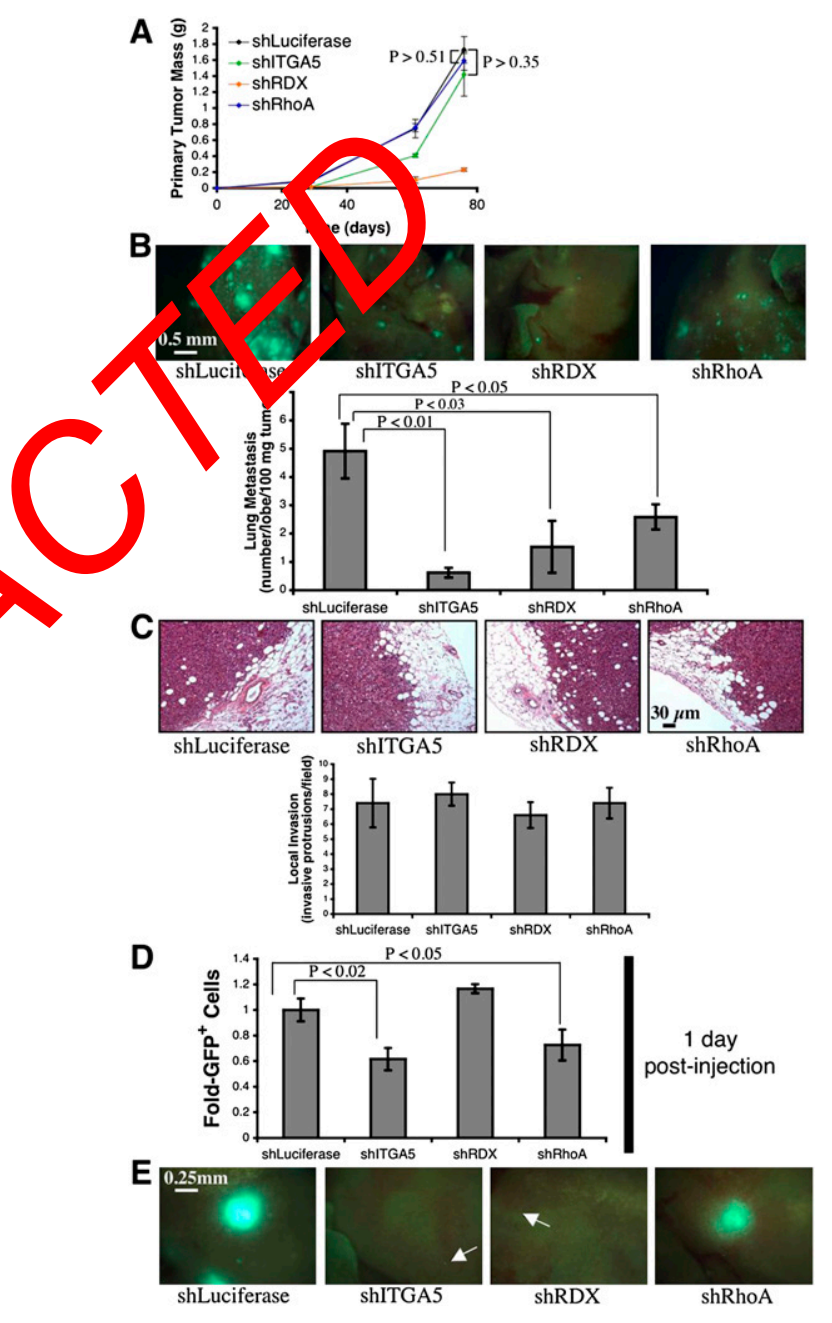

Figure 1. Individual suppression of ITGA5, RDX, or RhoA impairs metastasis in vivo. (A) Primary tumor growth upon orthotopic injection of the indicated GFP-labeled 231 cells into NOD/SCID mice. The assay was terminated after $11 \mathrm{wk}$ due to primary tumor burden. $n=5$ per time point. ( $B$, top panels) Fluorescent images of murine lungs to visualize 231 cells $76 \mathrm{~d}$ after orthotopic implantation. (Bottom panel) Quantification of metastatic burden. $n=5 .(C$, top panels) H\&E stain of 231 cell primary mammary tumors $57 \mathrm{~d}$ after injection. (Bottom panel) Quantification of local invasion. $n=$ 5. All $P$-values are $>0.67$ relative to shLuciferase. $(D)$ Prevalence of GFP-labeled 231 cells in the lungs $1 \mathrm{~d}$ after intravenous introduction into NOD/SCID mice. $n=4$. (E) Fluorescent images of murine lungs to visualize 231 cells $89 \mathrm{~d}$ after intravenous injection. (Arrows) Micrometastases. shRNAs used in these assays were shITGA5 \#4, shRDX \#3, and shRhoA \#5. All error bars represent mean \pm SEM. 
In our previous work, we observed that miR-31 impinges on three steps of the invasion-metastasis cascade in vivo: local invasion, early post-intravasation events (intraluminal viability, extravasation, and/or initial survival in distant tissues), and colonization (Valastyan et al. 2009). Consequently, we evaluated whether the individual suppression of ITGA5, RDX, or RhoA was sufficient to recapitulate one or more of miR-31's multiple effects on the metastatic process. We found that 231 cells containing shRNAs against either ITGA5, RDX, or RhoA formed primary tumors that appeared histologically invasive and were indistinguishable from controls (Fig. 1C). Thus, inhibition of ITGA5, RDX, or RhoA alone does not abolish local invasion in vivo.

Putative effects on early post-intravasation events were examined by quantifying shRNA-expressing 231 cells in the lungs $1 \mathrm{~d}$ after intravenous injection. Cells with either suppressed ITGA5 or RhoA were $40 \%$ and $30 \%$ less prevalent than controls, respectively; however, RDX knockdown did not reduce persistence in the lungs (Fig. 1D). These effects were not attributable to a differential ability of the cells to become lodged initially in the lung microvasculature, as equal numbers of cells were detected in the lungs $10 \mathrm{~min}$ after intravenous injection (Supplemental Fig. 7). These data indicated that inhibition of either ITGA5 or RhoA impairs early post-intravasation events in vivo.

To investigate potential effects on colonization (i.e., the capacity of disseminated single cells to yield large, multicellular metastases), the sizes of lung metastases in intravenously injected animals were analyzed 3 mo after implantation. 231 cells expressing either ITGA5-or RDX shRNAs formed only small micrometastases, hil RhoA shRNA-containing cells generated macr scop metastases comparable with those spawned $y$ c rol cells (Fig. 1E). Hence, suppression of eith ATGA or RDX alone prevents colonization in vivg

Together, these observations reveal a that, n bile individual suppression of ITGA5, RD, or thoA impairs one or more steps of the invasion-1 astasis cascade, inhibition of any one of these $\mathrm{p}$ ote $\mathrm{ns}$. one is unable to phenocopy the full spectru of miR-s impact on metastasis. This suggested tha Mk-o may achieve its influences on multiple distinct tages of the metastatic process via concomitant suppres ion of several downstream effectors. Provocatively, our loss-of-function analyses indicated that ITGA5, RDX, and RhoA act during at least partially distinct steps of the invasion-metastasis cascade (e.g., RhoA affected early post-intravasation events but not colonization, while RDX had no impact on early post-intravasation events but altered colonization); hence, their concurrent regulation provides a plausible mechanism by which miR-31 might elicit its multiple anti-metastatic effects.

To test this hypothesis, we stably re-expressed miRNAinsensitive mRNAs encoding ITGA5, RDX, and RhoA together in combination-along with either miR-31 or control vector-in 231 cells. When these cells were orthotopically injected into mice, miR-31 enhanced primary tumor growth, recapitulating our prior findings (Valastyan et al. 2009); simultaneous re-expression of ITGA5, RDX, and RhoA failed to alter the size of miR31-containing or control primary tumors (Fig. 2A). Despite their ability to generate larger primary tumors, miR31 -expressing 231 cells were impaired by $>80 \%$ in their
A
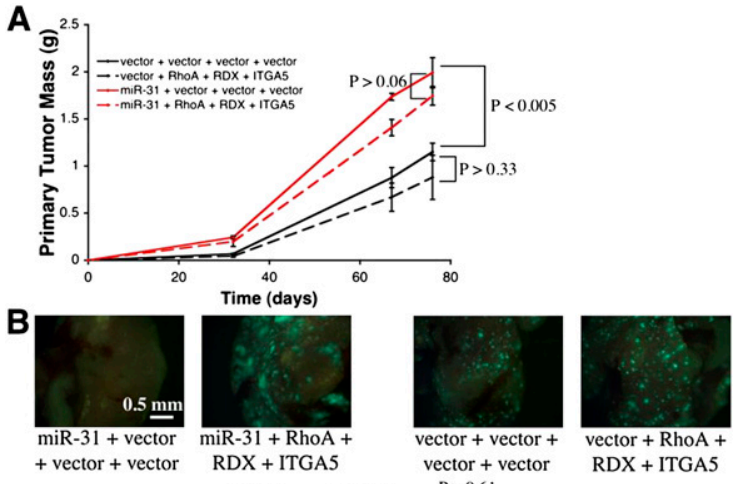

Figure 2. multan ous $r$ expression of ITGA5, RDX, and RhoA abrogates -31-im, metastasis suppression in vivo. (A) Primary tumor g. wth upw orthotopic injection of the indicated GFPlabe 31 cel into NOD/SCID mice. The assay was terminated af $11 \mathrm{wk}$ due primary tumor burden. $n=5$ per time point. $(B$, to panels/ luorescent images of murine lungs to visualize 231 cells 67 after o hotopic implantation. (Bottom panel) Quantification of met. atio ourden. $n=5$. All error bars represent mean \pm SEM.

ability to spawn lung metastases (Fig. 2B). ITGA5, RDX, and RhoA did not enhance metastasis in control 231 cells; however, concomitant re-expression of ITGA5, RDX, and RhoA in 231 cells containing miR-31 completely abrogated miR-31-imposed metastasis suppression (Fig. 2B). These data implied that the impact of miR-31 on in vivo metastasis can be explained by miR-31's capacity to inhibit a cohort of three downstream effectors. This was quite surprising, as computational algorithms predict that miR-31 regulates $>200$ mRNAs, many of which encode proteins that function in metastasis-relevant processes (Krek et al. 2005; Grimson et al. 2007).

Since the combined re-expression of ITGA5, RDX, and RhoA entirely abolished miR-31-evoked metastasis suppression, we also determined whether these three effectors were able to reverse a subset of miR-31's influences on metastasis when re-expressed either individually or in different combinations. Thus, we created 231 cells stably expressing miR-31 or control vector plus all possible permutations of zero, one, two, or three of these miR-31 targets (all rendered miRNA-resistant) (Supplemental Fig. 8). miR-31, ITGA5, RDX, and RhoA failed to affect cell proliferation in vitro (Supplemental Fig. 9A). However, individual re-expression of ITGA5, RDX, or RhoA rescued, at least partially, in vitro defects in invasion, motility, and anoikis resistance conferred by ectopic miR-31; the extent of reversal was more pronounced when multiple effectors were re-expressed in combination (Supplemental Fig. 9B-D).Thus, ITGA5, RDX, and RhoA control in vitro behaviors important for metastasis downstream from miR-31.

To assay the respective abilities of all possible combinations of re-expressed ITGA5, RDX, and/or RhoA to 
reverse miR-31's influences on in vivo metastasis, 231 cells expressing miR-31, ITGA5, RDX, and/or RhoA were orthotopically implanted into mice. miR-31 generally promoted primary tumor growth, while restored levels of ITGA5, RDX, and RhoA failed to consistently affect the growth of primary tumors (Fig. 3A; Supplemental Table 1). miR-31 reduced the incidence of metastatic lesions in the lungs by $>90 \%$ (Fig. 3B). When individually re-expressed in miR-31-containing cells, ITGA5, RDX, or RhoA increased metastasis to $40 \%, 45 \%$, and $65 \%$ of control levels, respectively; re-expression of any two of these targets in miR-31-positive cells yielded $85 \%$ as many metastases as controls (Fig. 3B). As before, concomitant re-expression of ITGA5, RDX, and RhoA in cells containing miR-31 restored the number of lung metastases to $100 \%$ of that observed in controls (Fig. 3B).

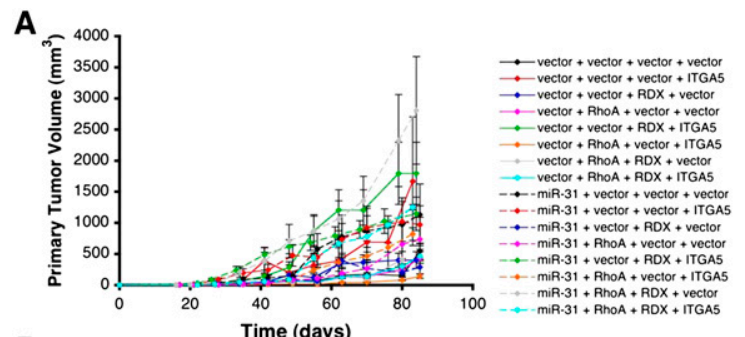

B
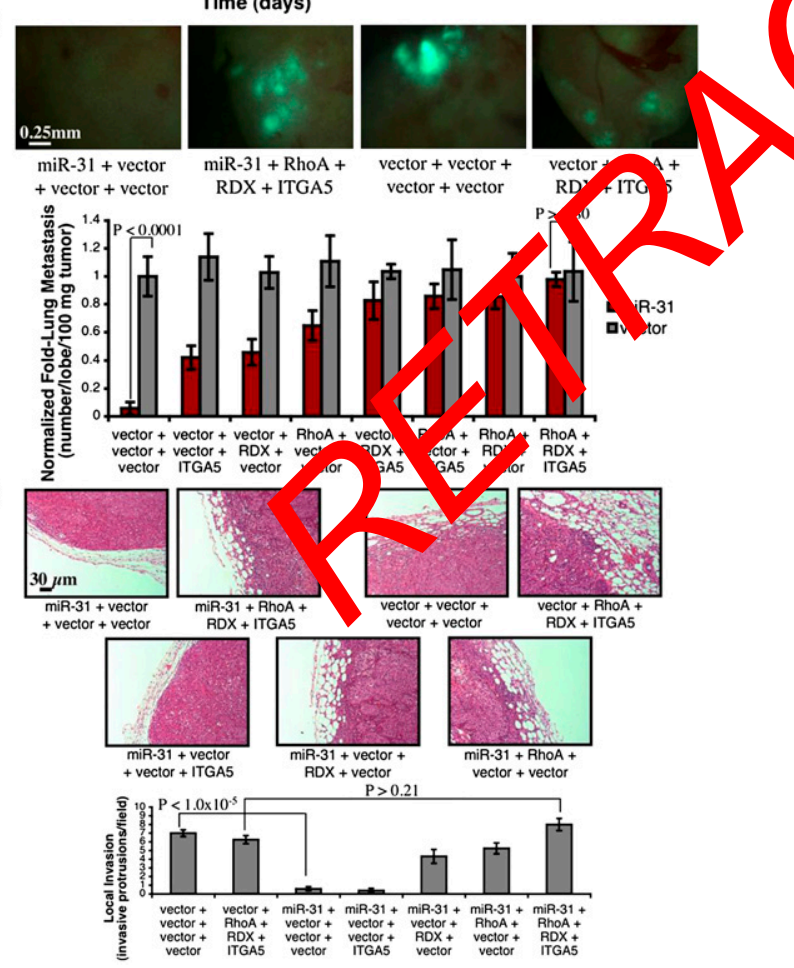

Figure 3. Re-expression of ITGA5, RDX, and/or RhoA affords both unique and partially overlapping reversal of miR-31-evoked inhibition of spontaneous metastasis in vivo. (A) Primary tumor growth upon orthotopic implantation of the indicated GFP-labeled 231 cells into nude mice. The assay was terminated after 13 wk due to primary tumor burden. $n=5$. ( $B$, top panels) Fluorescent images of murine lungs to visualize 231 cells $88 \mathrm{~d}$ after orthotopic injection. (Bottom panel) Quantification of metastatic burden. $n=5$. (C) H\&E stain of 231 cell primary mammary tumors $54 \mathrm{~d}$ after injection. (Bottom panel) Quantification of local invasion. $n=5$. All error bars represent mean \pm SEM.
Hence, these three effectors make distinct contributions to in vivo metastasis that can collaborate to explain miR31 's influence on this process; however, these observations failed to delineate the specific step(s) of the invasion-metastasis cascade affected by various combinations of re-expressed ITGA5, RDX, and/or RhoA.

miR-31 affects three steps of the invasion-metastasis cascade in vivo: local invasion, early post-intravasation events, and colonization (Valastyan et al. 2009). To investigate whether ITGA5, RDX, and RhoA-when overexpressed-could synergize to reverse miR-31's effects on local invasion, we examined the histological appearance of primary tumors that developed in orthotopically injected mice. Whereas control 231 cell tumors displayed clear evidence of invasion, miR-31-expressing tumors were well-confined (Fig. 3C), as we documented previously (Valastyan et al. 2009). While ITGA5, RDX, and RhoA did not alter invasion in control 231 cell tumors, combined re-expr oor of these three targets abolished the previously ell-en psulated phenotype of miR-31expressing ty no (Fig. 3 ). miR-31-containing cells with restored 1 vels of eitb or RDX or RhoA alone formed primary mo that ppeared invasive, although reversal of $\mathrm{m}-3 \mathrm{npose} \mathrm{d}$ invasion defects was incomplete; IT 5 did $n$ t ect encapsulation (Fig. 3C). These observation reveacd that miR-31-dependent attenuation of rocal in sion can be attributed to miR-31's ability to regulate RDX and RhoA. Ostensibly, in light of our shRNA stud es (Fig. 1C), RDX and RhoA function redundantly-

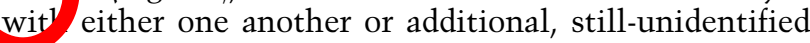
ImIR-31 targets - to promote invasion in vivo.

We also examined whether re-expression of these three targets could reverse the impact of miR-31 on early postintravasation events. To do so, we introduced 231 cells into the venous circulation of mice and assayed the number of cells in the lungs $1 \mathrm{~d}$ after injection. Consistent with our previous findings (Valastyan et al. 2009), miR31-expressing cells were fivefold impaired in their ability to persist in the lungs (Fig. 4A), indicating that miR-31 impeded one or more early post-intravasation events. ITGA5, RDX, and RhoA failed to affect early post-intravasation events in control 231 cells (Fig. 4A). In contrast, individual re-expression of either ITGA5 or RhoA restored the number of miR-31-expressing cells in the lungs to $50 \%$ of control levels; RDX did not augment the ability of cells containing miR-31 to persist in the lungs at this time point (Fig. 4A). Simultaneous reintroduction of ITGA5 and RhoA in miR-31-expressing cells sufficed to completely override miR-31-imposed obstruction of early post-intravasation events (Fig. 4A). These effects were not a consequence of an altered ability of ITGA5-, RDX-, RhoA-, and/or miR-31-expressing cells to become lodged initially in the lung microvasculature, as equal numbers of cells were detected in the lungs $10 \mathrm{~min}$ after intravenous injection (Supplemental Fig. 10). These data provided evidence that miR-31-evoked suppression of early post-intravasation events can be ascribed to miR-31's ability to modulate ITGA5 and RhoA.

Three months after intravenous injection, control 231 cells generated large macroscopic metastases while miR-31-expressing cells yielded only small micrometastases (Fig. 4B). Hence, miR-31 prevented disseminated tumor cells from reinitiating their proliferative program at the site of metastasis, in consonance with miR-31's reported influence on colonization (Valastyan et al. 2009). 
A

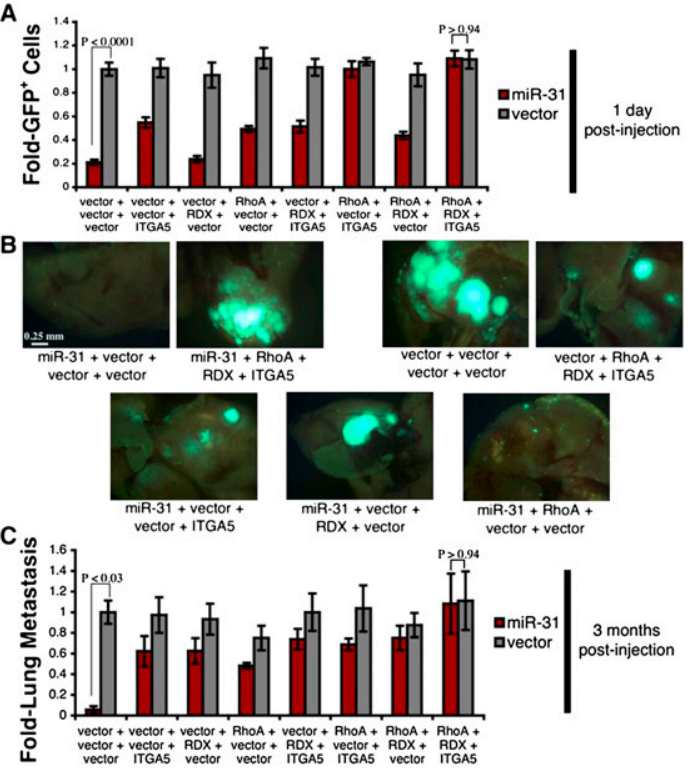

Figure 4. Re-expression of ITGA5, RDX, and/or RhoA affords both unique and partially overlapping reversal of miR-31-mediated inhibition of experimental metastasis in vivo. (A) Prevalence of the indicated GFP-labeled 231 cells in the lungs $1 \mathrm{~d}$ after intravenous introduction into NOD/SCID mice. $n=4$. (B) Fluorescent images of murine lungs to visualize 231 cells $84 \mathrm{~d}$ after tail vein injection. $(C)$ Lung metastatic burden $84 \mathrm{~d}$ subsequent to intravenous injection. $n=5$. All error bars represent mean \pm SEM.

Concomitant re-expression of ITGA5, RDX, and Rho miR-31-containing cells abrogated miR-31-impos a sup pression of colonization, yet overexpression on th three targets in control 231 cells failed to inc ase 1 ion size (Fig. 4B). Individually restored levels of $1 \mathrm{t}$ er ITC 45 or RDX in miR-31-expressing cells re ersed niR-31's effects on colonization; RhoA did not affect this yarameter (Fig. 4B). Thus, the ability or mip 31 to inhibit colonization can derive from ita cat aty th suppress ITGA5 and RDX.

In this same assay, miR-31- xpre sing 2.51 cells formed 20 -fold fewer lung metastases nan ountrols (Fig. 4C). When individually re-expressed in miR-31-containing cells, ITGA5, RDX, or RhoA indeased the number of metastases formed to $60 \%, 60 \%$, and $50 \%$ of control levels, respectively (Fig. 4C). Restored levels of pairwise combinations of these three targets in miR-31-expressing cells enhanced lesion number to $>70 \%$ of controls; importantly, simultaneous re-expression of ITGA5, RDX, and RhoA in miR-31-containing cells completely abolished miR-31-mediated metastasis suppression (Fig. 4C). Taken together, the preceding experiments indicated that the impact of miR-31 on metastasis can be entirely explained by miR-31's capacity to regulate ITGA5, RDX, and RhoA; these three targets act at partially overlapping steps of the invasion-metastasis cascade downstream from miR-31 in vivo (Table 1).

It remained possible that the ability of ITGA5, RDX, and RhoA to override miR-31's actions arose due to some peculiarity of the 231 cell system. To address this, we extended our analyses to SUM-159 human breast cancer cells. Like 231 cells, SUM-159 cells lack endogenous miR-31, are highly aggressive in vitro, and display impaired invasion, motility, and anoikis resistance upon ectopic miR-31 (Valastyan et al. 2009). We created SUM159 cells stably expressing all 16 potential combinations of either miR-31 or control vector plus miRNA-resistant mRNAs encoding ITGA5, RDX, and/or RhoA; all lines displayed comparable in vitro proliferative kinetics (Supplemental Fig. 11A,B). Consistent with our observations in 231 cells, individual re-expression of ITGA5, RDX, or RhoA in miR-31-containing SUM-159 cells rescued, at least partially, in vitro defects in invasion, motility, and anoikis resistance attributable to ectopic miR-31; as before, the extent of rescue was more pronounced when multiple effectors were concomitantly re-expressed (Supplemental Fig, 11C-E). Hence, the ability of ITGA5, RDX, and RhoA re-expression to override the actions of miR-31 is not confined to 231 cells.

Whereas individual re-expression of ITGA5, RDX, or RhoA largely reversed certain miR-31-imposed metastasis-relevant defects in vitro (Supplemental Figs. 9, 11), individual restoration $T$ TA5, RDX, or RhoA levels only partially rescue miR- 1 's effects on metastasis in vivo (Figs. 3, 4). This $u$ dersce es the fact that available in vitro assays ina cquat $\mathrm{v} \mathrm{m}$ del the full complexity of in vivo metas sis; aut must therefore be exercised when depl in nese techniques, particularly in the absence parall in ivo analyses.

Collectiv $\mathrm{l} y$, the mdings of the present study suggest that miRl A's effects on a given phenotype can be ex olained by $\mathrm{s}$ ability to suppress a relatively modest $\mathrm{n}$ mber 0 downstream targets. In the present case, the re vant $\&$ fectors comprise only a small percentage of the tota wer of mRNAs targeted by the miRNA under restigation. Our observations are confined to a single mikNA and a single biological endpoint; accordingly, the extent to which this phenomenon is generalizable awaits future investigation. Nevertheless, several recent studies describe strong, but partial, effects on miRNA-mediated phenotypes by modulating individual targets of miRNAs of interest (Ma et al. 2007; Xiao et al. 2007; Yu et al. 2007; Kumar et al. 2008). Such reports suggest the existence of other similarly organized miRNA response networks, in which a miRNA's impact on a biological process can be attributed to that miRNA's ability to inhibit only a small subfraction of its targets.

While our data indicate that ITGA5, RDX, and RhoA represent a minimal cohort of effectors whose regulation is sufficient to account for miR-31's impact on metastasis, these observations do not preclude the existence of additional miR-31 targets that impinge on metastasis-relevant pathways in a manner that ostensibly is functionally redundant with the actions of ITGA5, RDX, and/or RhoA. Also, it is possible that one or more bona fide targets of miR-31 that have metastatic relevance fail to be significantly down-regulated by this miRNA in 231 cells. Overall, due to the fact that metastases are responsible for the overwhelming majority of patient mortality from

Table 1. Summary of ability of re-expressed targets to rescue miR-31-imposed metastasis suppression

\begin{tabular}{lccc}
\hline Target & $\begin{array}{c}\text { Local } \\
\text { invasion }\end{array}$ & $\begin{array}{c}\text { Early } \\
\text { post-intravasation } \\
\text { events }\end{array}$ & $\begin{array}{c}\text { Metastatic } \\
\text { colonization }\end{array}$ \\
\hline ITGA5 & No rescue & $\sqrt{ }$ & $\sqrt{ }$ \\
RDX & $\sqrt{ }$ & No rescue & $\sqrt{ }$ \\
RhoA & $\sqrt{ }$ & $\sqrt{ }$ & No rescue \\
\hline
\end{tabular}


carcinomas, this study highlights the idea that modulation of miR-31 and its effectors may prove clinically useful.

\section{Materials and methods}

\section{Cell culture}

Green fluorescent protein (GFP)-labeled 231 cells have been described (Valastyan et al. 2009). SUM-159 cells were provided by S. Ethier (Ma et al. 2007). Stable expression was achieved via retroviral (expression constructs) or lentiviral (shRNAs) transduction, followed by selection with puromycin, neomycin, hygromycin, and/or zeocin (Elenbaas et al. 2001).

\section{Animal studies}

All research involving animals complied with protocols approved by the Massachusetts Institute of Technology (MIT) Committee on Animal Care. Age-matched NOD/SCID (propagated on site) or nude (Taconic) mice were used in the xenograft studies, as indicated. For spontaneous metastasis assays, the indicated female mice were bilaterally injected into the mammary fat pads with $1.0 \times 10^{6}$ tumor cells resuspended in $1: 2$ Matrigel (BD Biosciences) plus normal growth media. In spontaneous metastasis assays employing nude mice, primary tumor diameter was measured every $7 \mathrm{~d}$ using precision calipers; tumor volume was calculated according to the formula $V=(4 / 3) \prod r^{3}$. For experimental metastasis assays, the indicated mice were injected intravenously with $5.0 \times 10^{5}$ tumor cells (in PBS) via the tail vein. Lung metastasis was quantified using a fluorescent dissecting microscope within $3 \mathrm{~h}$ of specimen isolation. Tumor histology was assessed by staining paraffin-embedded tissue sections with hematoxylin and eosin (H\&E).

\section{Statistical analysis}

Data are presented as mean \pm SEM; Student's two-tailed $t$-t for comparisons, with $P<0.05$ considered significant.

\section{Acknowledgments}

We thank Julie Valastyan and Sandra McAllistar for cr cal readng of this manuscript; M. Saelzler, L. Waldman, and o Aer membe of the Weinberg laboratory for discussions; G. Bokoch, S rouct P. Klein S. Kuwada, H. Surks, and S. Weiss for reagents; and M. Bro $\mathrm{n}$ and the Koch Institute Histology Facility for tissue sectir the rese th was supported by the NIH (RO1 CA078461), MIT Ludwi Cen rr or Molecular Oncology, U.S. Department of Defense, east ancer Kesearch Foundation, and DoD BCRP Idea Award. S.V. a R.A.W. are inventors on a patent application in part based on findin detailed in this manuscript. S.V. is a U.S. Department of Defense Bre t Cancer Research Program Predoctoral Fellow. R.A.W. is an American Cancer Society Research Professor and a Daniel K. Ludwig Foundation Cancer Research Professor.

\section{References}

Ambros V. 2004. The functions of animal microRNAs. Nature 431: 350355.

Baek D, Villén J, Shin C, Camargo FD, Gygi SP, Bartel DP. 2008. The impact of microRNAs on protein output. Nature 455: 64-71.

Bartel DP. 2009. MicroRNAs: Target recognition and regulatory functions. Cell 136: 215-233.

Elenbaas B, Spirio L, Koerner F, Fleming MD, Zimonjic DB, Donaher JL, Popescu NC, Hahn WC, Weinberg RA. 2001. Human breast cancer cells generated by oncogenic transformation of primary mammary epithelial cells. Genes \& Dev 15: 50-65.

Fidler IJ. 2003. The pathogenesis of cancer metastasis: The 'seed and soil' hypothesis revisited. Nat Rev Cancer 3: 453-458.

Grimson A, Farh KK, Johnston WK, Garrett-Engele P, Lim LP, Bartel DP. 2007. MicroRNA targeting specificity in mammals: Determinants beyond seed pairing. Mol Cell 27: 91-105.

Gupta GP, Massagué J. 2006. Cancer metastasis: Building a framework. Cell 127: 679-695.
Johnnidis JB, Harris MH, Wheeler RT, Stehling-Sun S, Lam MH, Kirak O, Brummelkamp TR, Fleming MD, Camargo FD. 2008. Regulation of progenitor cell proliferation and granulocyte function by microRNA223. Nature 451: 1125-1129.

Krek A, Grün D, Poy MN, Wolf R, Rosenberg L, Epstein EJ, MacMenamin P, da Piedade I, Gunsalus KC, Stoffel M, et al. 2005. Combinatorial microRNA target predictions. Nat Genet 37: 495-500.

Kumar MS, Erkeland SJ, Pester RE, Chen CY, Ebert MS, Sharp PA, Jacks T. 2008. Suppression of non-small cell lung tumor development by the let-7 microRNA family. Proc Natl Acad Sci 105: 3903-3908.

Ma L, Teruya-Feldstein J, Weinberg RA. 2007. Tumour invasion and metastasis initiated by microRNA-10b in breast cancer. Nature 449: 682-688.

Pillé JY, Denoyelle C, Varet J, Bertrand JR, Soria J, Opolon P, Lu H, Pritchard LL, Vannier JP, Malvy C, et al. 2005. Anti-RhoA and antiRhoC siRNAs inhibit the proliferation and invasiveness of MDA-MB231 breast cancer cells in vitro and in vivo. Mol Ther 11: 267-274.

Rodriguez A, Vigorito E, Clare S, Warren MV, Couttet P, Soond DR, van Dongen S, Grocock RJ, Das PP, Miska EA, et al. 2007. Requirement of bic/microRNA-155 for normal immune function. Science 316: 608611.

Selbach M, Schwanh sser b, Thierfelder N, Fang Z, Khanin R, Rajewsky N. 2008. Widesp ad chan $s$ in protein synthesis induced by microRNAs. Nat e 45, 58-63.

Thai TH, C.do DP, o sol s, Ansel KM, Xiao C, Xue Y, Murphy A, Frender v D Valenz Aa D, Kutok JL, et al. 2007. Regulation of ger inal ter res onse by microRNA-155. Science 316: 604-608.

Vala n S, Rø har F, Benaich N, Calogrias D, Szász AM, Wang ZC, Broc JE, Ric dson AL, Weinberg RA. 2009. A pleiotropically acting micro NA, miR-31, inhibits breast cancer metastasis. Cell 137: $1032-106$.

van P oij E, Sutherland LB, Qi X, Richardson JA, Hill J, Olson EN. 2007. C htrol of stress-dependent cardiac growth and gene expression by microRNA. Science 316: 575-579.

ventura A, Jacks T. 2009. MicroRNAs and cancer: Short RNAs go a long way. Cell 136: 586-591.

Ventura A, Young AG, Winslow MM, Lintault L, Meissner A, Erkeland SJ, Newman J, Bronson RT, Crowley D, Stone JR, et al. 2008. Targeted deletion reveals essential and overlapping functions of the miR-17 through 92 family of miRNA clusters. Cell 132: 875-886.

Xiao C, Calado DP, Galler G, Thai TH, Patterson HC, Wang J, Rajewsky N, Bender TP, Rajewsky K. 2007. MiR-150 controls B cell differentiation by targeting the transcription factor c-Myb. Cell 131: 146-159.

Yu F, Yao H, Zhu P, Zhang X, Pan Q, Gong C, Huang Y, Hu X, Su F, Lieberman J, et al. 2007. Let-7 regulates self renewal and tumorigenicity of breast cancer cells. Cell 131: 1109-1123.

Zhao Y, Ransom JF, Li A, Vedantham V, von Drehle M, Muth AN, Tsuchihashi T, McManus MT, Schwartz RJ, Srivastava D. 2007. Dysregulation of cardiogenesis, cardiac conduction, and cell cycle in mice lacking miRNA-1-2. Cell 129: 303-317. 


\section{Retraction}

Genes \& Development 23: 2592-2597 (2009)

\section{Concomitant suppression of three target genes can explain the impact of a microRNA on metastasis}

Scott Valastyan, Nathan Benaich, Amelia Chang, Ferenc Reinhardt, and Robert A. Weinberg

"Our study investigated the mechanisms by which miR-31 regulates different aspects of breast cancer metastasis. We have retracted our earlier publication involving miR-31 (Valastyan et al. 2009) because original data were compiled from different replicate experiments in order to assemble certain figure panels. As the same analytical methodology was used in this manuscript, we believe that the responsible course of action is to retract the article. We apologize for any inconvenience we have caused."

The cosigners of this retraction are the same set of coauthors as that of the Genes 4 Development article.

\section{Reference}

Valastyan S, Reinhardt F, Benaich N, Calogrias D, Szasz AM, Wang ZC, Brock JE, Richardson AL, Weinberg RA. 2009. A pleiotropically acting microRNA, miR-31, inhibits breast cancer metastasis. Cell 137: 1032-1046.

\section{Retraction}

Genes \& Development 25: 646-659 (2011)

\section{Activation of miR-31 function in already-established metastases elicits metastatic regression}

Scott Valastyan, Amelia Chang, Nathan Benaich, Ferenc Reinhardt, and Robert A. Weinberg

"Our study investigated the mechanisms by which miR-31 regulates different aspects of breast cancer metastasis. We have retracted our earlier publication involving miR-31 (Valastyan et al. 2009) because original data were compiled from different replicate experiments in order to assemble certain figure panels. As the same analytical methodology was used in this manuscript, we believe that the responsible course of action is to retract the article. We apologize for any inconvenience we have caused."

The cosigners of this retraction are the same set of coauthors as that of the Genes $\uplus$ Development article.

\section{Reference}

Valastyan S, Reinhardt F, Benaich N, Calogrias D, Szasz AM, Wang ZC, Brock JE, Richardson AL, Weinberg RA. 2009. A pleiotropically acting microRNA, miR-31, inhibits breast cancer metastasis. Cell 137: 1032-1046. 


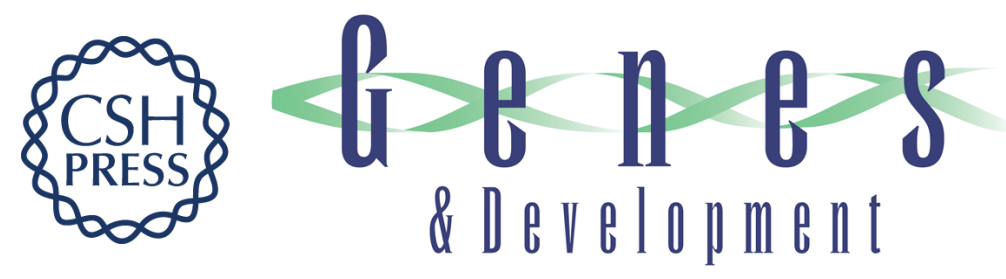

\section{Concomitant suppression of three target genes can explain the impact of a microRNA on metastasis}

Scott Valastyan, Nathan Benaich, Amelia Chang, et al.

Genes Dev. 2009, 23: originally published online October 29, 2009

Access the most recent version at doi:10.1101/gad.1832709

\section{Supplemental http://genesdev.cshlp.org/content/suppl/2009/09/29/gad.1832709.DC1 \\ Material}

Related Content

Concomitant suppression of three target genes can explain the impact of a microRNA on metastasis

Scott Valastyan, Nathan Benaich, Amelia Chang, et al.

Genes Dev. March , 2015 29: 686.1

References This article cites 22 articles, 5 of which can be accessed free at:

http://genesdev.cshlp.org/content/23/22/2592.full.html\#ref-list-1

Articles cited in:

http://genesdev.cshlp.org/content/23/22/2592.full.html\#related-urls

\section{License}

Email Alerting
Service

Receive free email alerts when new articles cite this article - sign up in the box at the top right corner of the article or click here.

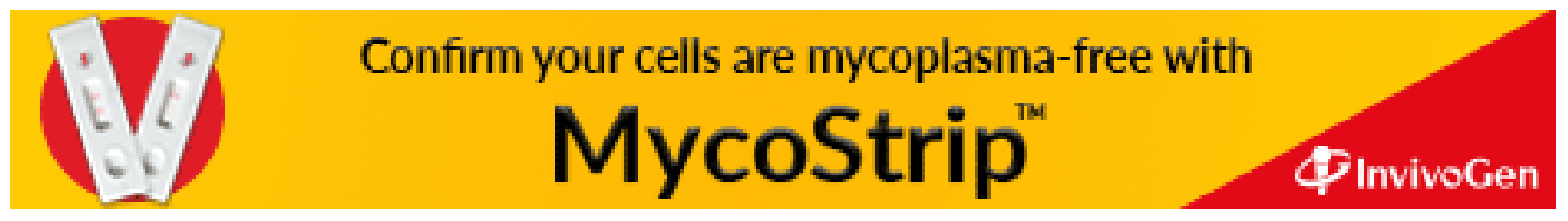

